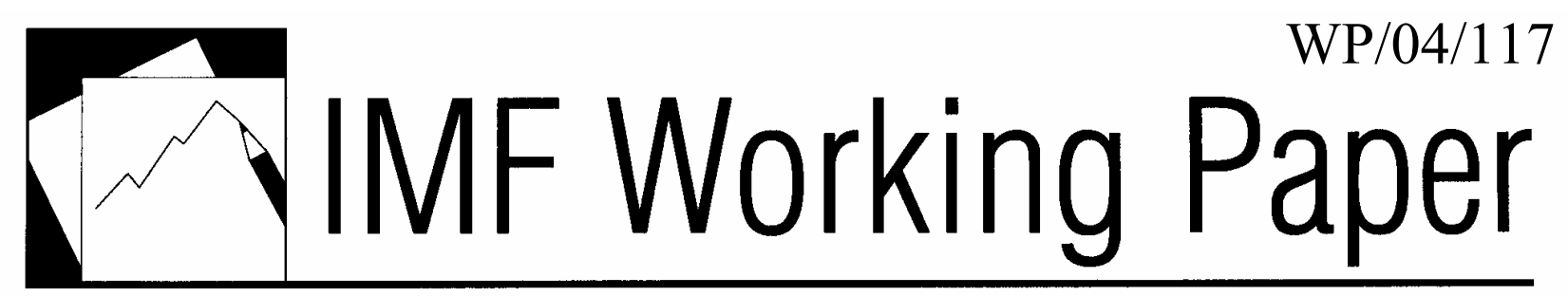

\title{
On Fixed and Variable Fiscal Surplus Rules
}

\author{
Erdem Basci, M. Fatih Ekinci, \\ and Murat Yulek
}




\title{
IMF Working Paper
}

\author{
African Department
}

\section{On Fixed and Variable Fiscal Surplus Rules}

\author{
Prepared by Erdem Basci, M. Fatih Ekinci, and Murat Yulek ${ }^{1}$ \\ Authorized for distribution by Lelde Schmitz
}

July 2004

\begin{abstract}
This Working Paper should not be reported as representing the views of the IMF. The views expressed in this Working Paper are those of the author(s) and do not necessarily represent those of the IMF or IMF policy. Working Papers describe research in progress by the author(s) and are published to elicit comments and to further debate.
\end{abstract}

Fiscal rules are being increasingly used by both emerging and developed economies. This paper analyzes two alternative fiscal policy rules in terms of their impact on debt sustainability: a rule that fixes the ratio of primary surplus to GDP ("fixed surplus rule") and one that sets the primary surplus as a linear function of debt to GDP ratio ("variable surplus rule"). A simple debt dynamics equation, incorporating real shocks, is constructed, and the probability of exceeding the critical debt level is simulated using Monte Carlo techniques. The results show that the variable surplus rule performs better than the simple fixed surplus rule, by reducing debt sustainability concerns and the necessary medium-term primary surplus. This result hinges on the government's ability to make a credible commitment to the variable surplus rule in the medium run.

JEL Classification Numbers: C15, E63, H63

Keywords: Debt dynamics, Monte-Carlo simulation, fiscal policy rules, debt sustainability Author’s E-Mail Address: erdem.basci@tcmb.gov.tr, mfekinci@uh.edu, myulek@imf.org

\footnotetext{
${ }^{1}$ The authors are with the Central Bank of the Republic of Turkey, University of Houston, and the International Monetary Fund. We thank, without implication, the participants of the 4th Annual Missouri Economic Conference (April 2004), Lelde Schmitz, Charalambos Tsangarides, Bent Sorensen, Emin Dinlersoz and Paulo Manasse for helpful comments. Mr. Basci would like to state that the views expressed in this Working Paper do not necessarily represent those of the Central Bank of the Republic of Turkey.
} 


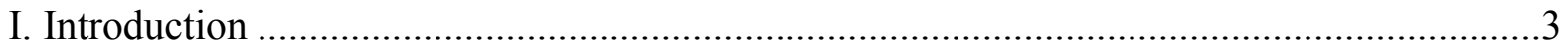

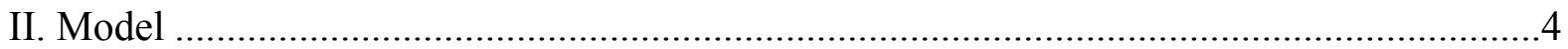

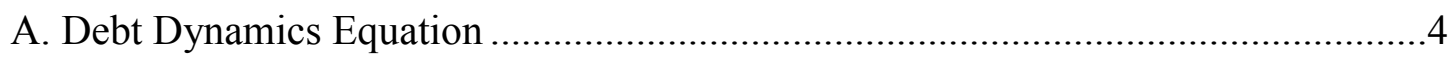

B. Alternative Fiscal Policy Rules .......................................................................... 5

C. Critical Debt Ratio and Sustainability............................................................6

D. Properties of Fiscal Policy Rules .................................................................

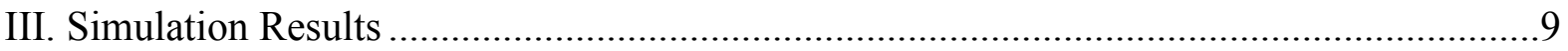

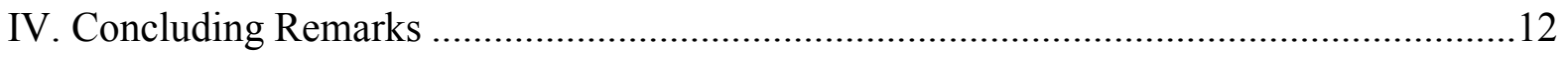

Figures

1. Probability Distributions of Exceeding the Critical Debt Levels ..................................8

2. Cumulative Probability of Exceeding the Critical Debt Ratio (Next Period) ..................10

3. Cumulative Probability of Exceeding the Critical Debt Ratio (Medium Term) .............11

4. Average Debt Ratio (Medium Term) ............................................................ 11

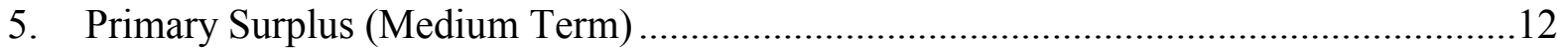

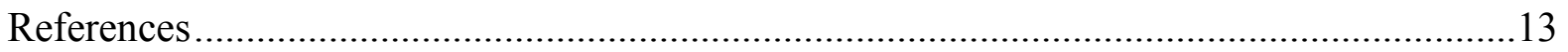




\section{INTRODUCTION}

Public debt levels have remained a significant macroeconomic issue for developing countries and international investors at least since the debt crises of the 1980s, especially in countries with a weak reputation for fiscal prudence. ${ }^{2}$ These countries range from relatively higher income countries, such as some Latin American countries and Turkey, to lower income countries such as those in Africa. ${ }^{3}$

Policies adopted in response to high debt levels and reactions by the international community vary. The international community adopted the enhanced Heavily Indebted Poor Countries (HIPC) initiative to eliminate the negative effect of the debt overhang on the development of lower income countries. In some relatively higher income countries with market access but lacking a record of fiscal prudence, fiscal rules have been adopted as a useful tool for fostering economic stability and growth. ${ }^{4,5}$

In countries with high debt-to-GDP ratios, such as Brazil and Turkey, the fixed primary surplus rule, which fixes the ratio of primary budget surplus to GDP, is being used as one form of fiscal rule, either to signal policy credibility, or to limit public debt levels, or both. In this paper we run numerical simulations (Monte Carlo technique) to compare the performance of the fixed primary surplus rule to an alternative, the variable primary surplus rule, under which the primary budget surplus is explicitly defined as an increasing function of the debt-to-GDP ratio. As the criterion of comparison, we use the probability of exceeding the sustainable debt level at the end of the simulation horizon starting from a given initial debt level. The results indicate that, provided the government can credibly commit to a variable surplus rule, it performs better than the fixed surplus rule as it reduces debt sustainability concerns as well as the necessary level of the medium-term primary surplus compared to the fixed surplus rule.

The paper is organized as follows. Section II develops the model, and the analytical definitions of the two fiscal rules and debt sustainability. The results of the numerical simulations are presented in Section III. Section IV presents the conclusions.

\footnotetext{
${ }^{2}$ Public debt and size of government are concerns for policymakers in developed countries as well (Daban and others, 2003).

${ }^{3}$ In some of these countries, the public debt is composed mostly of external debt, while in others domestic debt is also involved.

${ }^{4}$ Kopits (2001).

${ }^{5}$ Whether based on explicit fiscal rules or not, prudent fiscal policy is generally correlated positively with lower debt levels (Wyplosz, 2002).
} 


\section{MODEL}

\section{A. Debt Dynamics Equation}

The public sector debt dynamics of a country can be expressed as ${ }^{6}$

$$
D_{t+1}=\left(1+R_{t}\right)\left(D_{t}-P S_{t}\right)
$$

where, $D_{t}, P S_{t}$ and $R_{t}$ denotes respectively the debt stock ${ }^{7}$ at the beginning of period $\mathrm{t}$, the primary surplus in period $t$ (assumed to occur instantaneously at the beginning of period $t$ ) and the real interest rate in period $t$. Both the debt stock and the primary surplus are in real terms. The primary surplus is the difference between gross budgetary revenues and noninterest budgetary expenditures, i.e. $P S_{t}=T_{t}-G_{t}$, where, $T_{t}$ is the real budgetary revenues, and $G_{t}$ is the real non-interest budgetary expenditures. Therefore, the primary surplus has a decreasing effect on end-of-period debt stock.

The path of real output is given by

$$
Y_{t+1}=\left(1+g_{t}\right) Y_{t,},
$$

where $g_{t}$ is the real GDP growth rate.

Defining, the debt to GDP ratio as $d_{t}=D_{t} / Y_{t}$ and combining (1) and (2),

$$
d_{t+1}=\left[\left(1+R_{t}\right) /\left(1+g_{t}\right)\right]\left(d_{t}-p s_{t}\right)
$$

where $p s_{t}=P S_{t} / Y_{t}$.

Assuming $R_{t}$ and $g_{t}$ have random components, we define the random variable, $r_{t+} \varepsilon_{t}$, the growth adjusted real interest rate, through the following decomposition:

$$
1+r_{t}+\varepsilon_{t}=\frac{\left(1+R_{t}\right)}{\left(1+g_{t}\right)},
$$

\footnotetext{
${ }^{6}$ Note that this assumes no financing of the contemporaneous budget deficit by issuance of high powered money.

${ }^{7}$ We do not distinguish between domestic and external debt in this paper.
} 
where $r_{t}$ is the deterministic component of the real growth adjusted interest rate, and $\varepsilon_{t}$ is a zero mean independently and identically distributed (iid) random variable which represents the interest rate, and growth shocks. ${ }^{8}$

Next, we assume that the deterministic component of the growth adjusted mean real interest rate, $r\left(d_{t}\right)$ is an increasing function of the debt to GDP ratio. ${ }^{9}$

$$
r_{t}=r\left(d_{t}\right) \text { with } r^{\prime}\left(d_{t}\right)>0 \text {, }
$$

where $r^{\prime}\left(d_{t}\right)$ represents the first derivative of $r\left(d_{t}\right)$

Combining (3), (4), and (5), we obtain,

$$
d_{t+1}=\left(1+r\left(d_{t}\right)+\varepsilon_{t}\right)\left(d_{t}-p s_{t}\right) \text {, }
$$

where $d_{t}$ denotes debt to GDP ratio at the beginning of period $\mathrm{t}$, and $p s_{t}$ denotes the ratio of primary surplus to GDP in period t. We assume that growth adjusted mean real interest rate, $r\left(d_{t}\right)$ is an increasing function of the debt to GDP ratio.

\section{B. Alternative Fiscal Policy Rules}

We consider two alternative fiscal policy rules:

Rule 1: Fixed primary surplus. The fixed primary surplus rule is equal to a constant s percent of GDP at every period: $p s_{t}=s$ for all $\mathrm{t}$.

Rule 2: Variable primary surplus. Primary surplus is defined as a linearly increasing function of the debt stock; a higher fiscal surplus (a tighter fiscal policy) is set as the debt stock increases: $p s_{t}=\sigma d_{t}$ for all $\mathrm{t}, \sigma>0$.

\footnotetext{
${ }^{8}$ In the more generalized case where distinction is made between the domestic and external debt, the random term would also cover the real exchange rate shocks.

${ }^{9} \mathrm{Hu}$ and others (2001) provide evidence for a significant negative relationship between debt to GDP ratios and credit ratings, and thus a positive one with interest rates. Likewise, Cantor and Packer (1996) also show that lower external debt is consistent with higher credit ratings.
} 


\section{Critical Debt Ratio and Sustainability}

We define the critical debt ratio $\left(d_{c}\right)$ as the steady state of the deterministic version of the debt ratio as follows:

$$
\mathrm{E}\left[d_{t+1}\right]=d_{t}=d_{c}
$$

The critical debt level can be shown to be an unstable equilibrium. ${ }^{10}$ We use this property to define the debt level as sustainable when it is below the critical debt level.

Critical debt ratio can be computed for both fixed and variable rules by using relation (7). For simplicity, we will define. ${ }^{11}$

$$
r\left(d_{t}\right)=\rho d_{t} \text { for all } \mathrm{t}
$$

where, $0<\rho<1$.

For the fixed surplus rule $\left(p s_{t}=s\right)$, setting $\mathrm{E}\left[d_{t+1}\right]=d_{t}=d_{c}$, equation (6) becomes,

$$
\rho d_{c}^{2}-s \rho d_{c}-s=0
$$

In this case, critical debt level can be calculated as,

$$
d_{c}=\frac{\left(s \rho+\left(\sqrt{(s \rho)^{2}+4 s \rho}\right)\right)}{2 \rho},
$$

as $\mathrm{s}, \rho>0$ so that $\mathrm{s} \rho<\sqrt{(s \rho)^{2}+4 s \rho}$.

For the variable surplus rule $\left(p s_{t}=\sigma d_{t}\right)$ for all $\mathrm{t}$, critical debt level, $d_{c}$, becomes,

$$
d_{c}^{\prime}=\sigma / \rho(1-\sigma)
$$

Note that the critical debt ratio is policy dependent under both rules.

${ }^{10}$ See proposition 3 for the proof.

${ }^{11}$ See Catao and Kapur (2004) for a kinked version of the real interest rate function. Since we limit the analysis here to the neighborhood of the critical debt levels in the context of a hypothetical emerging country, we assumed a linear function for simplicity. Other nonlinear monotonic functions of debt ratio for the growth adjusted real interest rate do not change the main conclusions. We also assume that real interest rate is independent of the fiscal rule adopted. 


\section{Properties of Fiscal Policy Rules}

Let $d_{c}$ and $d_{c}{ }^{\prime}$ denote the critical debt levels of the constant surplus rule, and the variable surplus rule respectively.

Proposition 1: Given any initial debt ratio, $d_{0}$, and any fixed surplus rule, $p s_{t}=s$ for all $\mathrm{t}$ that makes expected debt dynamics sustainable, there exists an alternative linear surplus rule, the variable surplus rule, $p s_{t}=\sigma d_{t}$, that dominates the former by alleviating sustainability concerns, i.e., $d_{c}<d_{c}{ }^{\prime}$.

Proof: The initial debt ratio is below the critical debt level of constant surplus rule $\left(d_{0}<d_{c}\right)$. In the variable surplus rule, let $\sigma=s / d_{0}$ so that primary surplus is determined as $p s_{t}=\sigma d_{t}$. Critical debt levels for constant and variable surplus rules are given by equations (10) and (11). In this construction, $d_{c}{ }^{\prime}=s / \rho\left(d_{0}-s\right)$. We need to show $d_{c}<d_{c}{ }^{\prime}$.

Suppose not, $d_{c} \geq d_{c}{ }^{\prime}$, then,

$$
d_{c} \geq s / \rho\left(d_{0}-s\right)
$$

After rearranging (12) with the assumption $\left(d_{0}>s\right)$,

$$
d_{0} \geq s / \rho d_{c}+s
$$

By (13) and $d_{0}<d_{c}$,

$$
d_{c}>s / \rho d_{c}+s
$$

which implies

$$
\rho d_{c}^{2}-s \rho d_{c}-s>0
$$

which contradicts equation (9).

Q.E.D.

Proposition 1 shows that the fixed primary surplus levels may be improved upon by a variable surplus rule as it increases the critical debt ratio and alleviates sustainability concerns. This implicitly assumes that the government can credibly commit to a variable surplus rule. 


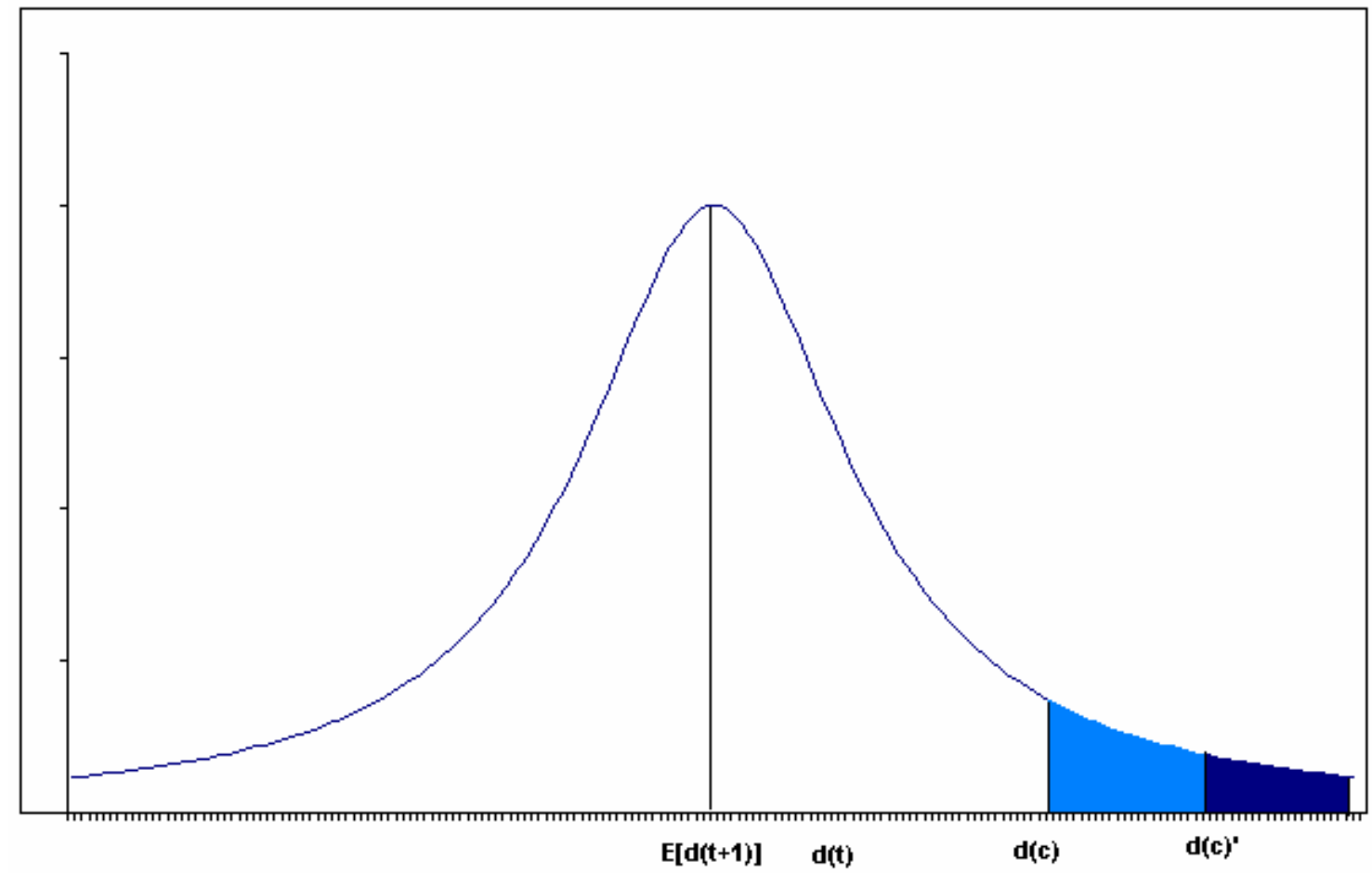

Figure 1. Probability Distribution of Exceeding the Critical Debt Levels at $d_{t}$ and $\mathrm{E}\left[d_{t+1}\right]$. ( $d(c)$ and $d(c)$ ' denote, respectively, the critical debt level for the fixed surplus rule and the variable surplus rule)

Proposition 2: Given any initial debt ratio, $d_{0}$, and any fixed surplus rule, $p s_{t}=s$ for all t that makes expected debt dynamics sustainable, there exists an alternative variable surplus rule, $p s_{t}=\sigma d_{t}$, that dominates the former by reducing the average primary surplus that corresponds to the fixed rule in the medium term.

\section{Proof: Trivial.}

Proposition 3: For both the fixed and variable primary surplus rules, the critical debt ratio is an unstable equilibrium.

Proof: When $p s_{t}=s$ and $r\left(d_{t}\right)=\rho d_{t}$ are substituted in the fixed surplus rule, the dynamics becomes,

$$
\mathrm{E}\left[\Delta d_{t+1}\right]=\rho d_{t}^{2}-s-s \rho d_{t}
$$

By (10) and (16), $\mathrm{E}\left[\Delta d_{t+1}\right]>0$ when $d_{t}>d_{c}$ and $\mathrm{E}\left[\Delta d_{t+1}\right]<0$ when $d_{t}<d_{c}$; the critical debt level is an unstable equilibrium for the fixed surplus rule. 
For the variable surplus rule $\left(p s_{t}=\sigma d_{t}\right)$, the dynamics can be written as

$$
\mathrm{E}\left[\Delta d_{t+1}\right]=d_{t}\left(\rho d_{t}-\sigma \rho d_{t}-\sigma\right)
$$

By (11) and (17), debt ratio diverges from the equilibrium point $\left(d_{c}^{\prime}\right)$; the critical debt level is an unstable equilibrium for the variable surplus rule.

Therefore, when $d_{t}>d_{c}$, debt level blows up, and it tends to decline when $d_{t}<d_{c}$ under both fiscal rules.

\section{Simulation Results}

We used the results in the previous sections to conduct simulations for both fiscal rules using Monte Carlo technique, for initial debt ratios $\left(d_{0}\right)$ ranging from 20 percent of GDP to 100 percent of GDP. First, the debt ratio at the next period was calculated with normally distributed random shocks by using equation (6); subsequently, quantitative results have been obtained for 1000 Monte Carlo trials, repeating the same shocks under both fiscal rules. Arithmetic averages of these trials are used in the quantitative analysis.

In the simulations, $\rho$ is set at 10 percent so that a debt ratio of, say, 60 percent corresponds to 6 percent growth adjusted real interest rate. ${ }^{12}$ Other levels for $\rho^{13}$ for the growth adjusted real interest rate do not change the main conclusions from the analysis. Shocks to debt dynamics, $\varepsilon_{t}$, assumed to be iid with a normal distribution, is set to have zero mean, and 5 percent variance.

For the numerical simulations, we set the parameters for the two policy rules as follows:

Fixed surplus rule: $p s_{t}=0.04 \quad \forall t$ (corresponding to $d_{c}=0.6528$ ).

Variable surplus rule: $\sigma=0.0667$ and thus $p s_{t}=0.0667 d_{t} \forall t$ (corresponding to $d_{c}^{\prime}=$ $0.7143)$.

These variable and fixed surplus rules require the same primary surplus at 60 percent initial debt ratio, which is below the critical level of the fixed rule. The initial debt level in the simulations is, thus, below the critical debt $\left(d_{0}<d_{c}\right)$. In our set up, the probability of

\footnotetext{
${ }^{12}$ With a real GDP growth of, say, 5 percent, this translates into a real interest rate of 11 percent from Equation 5.

13 The conclusions from the simulations are not effected by different values of $\rho$ provided that the policy rule for the variable surplus rule $(\sigma)$ is adjusted appropriately.
} 
exceeding the critical debt ratio corresponds to one minus the probability of maintaining the debt sustainability. ${ }^{14}$

The results of the numerical simulations show that the variable surplus rule dominates the fixed surplus rule for both horizons; the cumulative probability of explosion in the next period or over the medium term is higher for the fixed surplus rule than for the variable surplus rule. The results are displayed in Figures 2 and 3 where the horizontal and the vertical axis show the initial debt ratio, and the cumulative probability of explosion from the simulations, respectively.

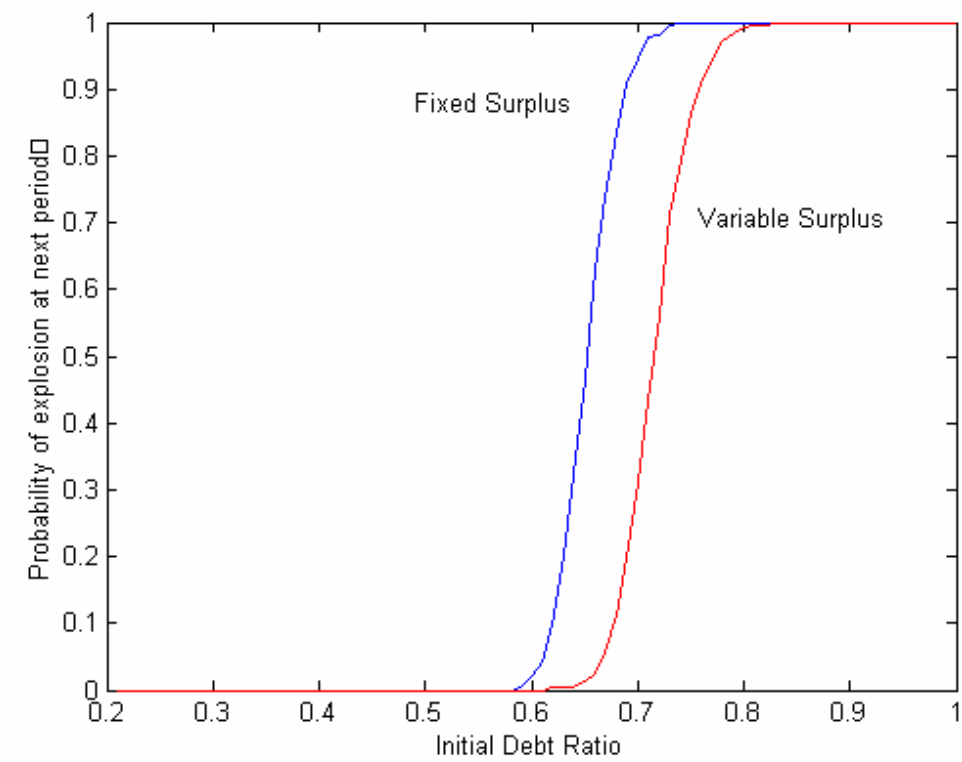

Figure 2. Cumulative Probability of Exceeding the Critical Debt Ratio at the End of the Next Period.

${ }^{14}$ Simulations for both the next-period (next year) and for the medium term (five years) were run for both rules. With the parameters selected as above for each rule, exceeding the critical debt ratio at the end of the next period (or the medium term) is not possible under both rules when the simulations start from an initial debt ratio of less than 50 percent of the GDP. Likewise, to have a sustainable debt ratio in the next period (or in the medium run) is practically not possible when the simulations are started with an initial debt ratio of higher than 80 percent (of GDP) for either rule. For an initial debt level higher than 80 percent of GDP, policy makers would need to further tighten the fiscal policy to raise the primary surplus, thus raising the critical debt level and rendering the debt dynamics sustainable. 


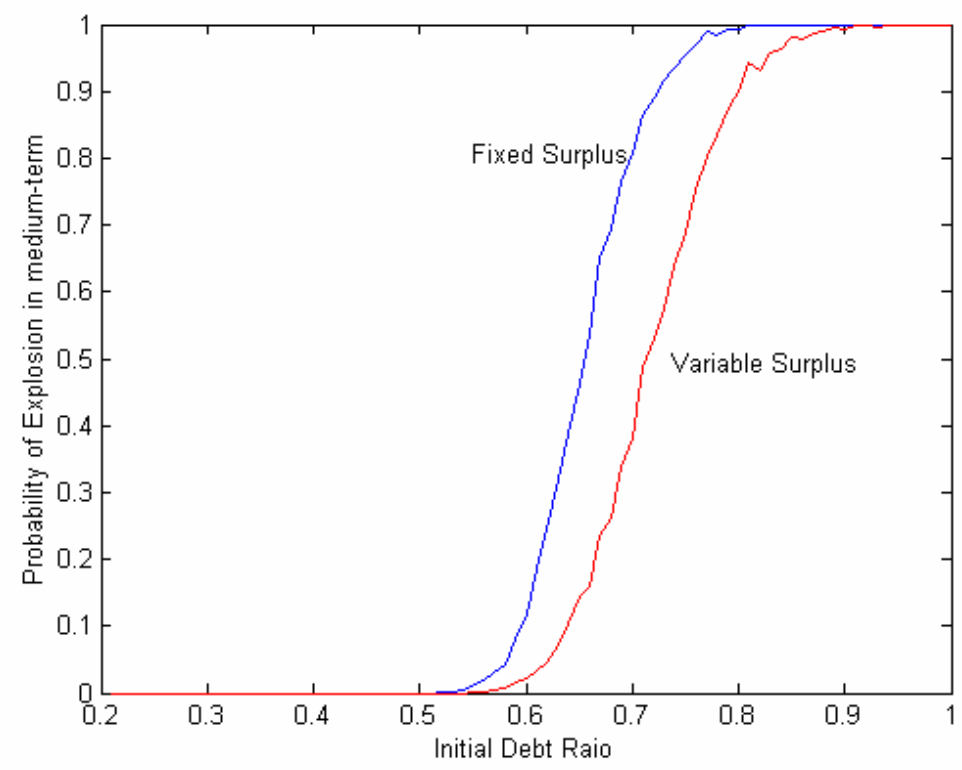

Figure 3. Cumulative Probability of Exceeding the Critical Debt Ratio in the Medium Term

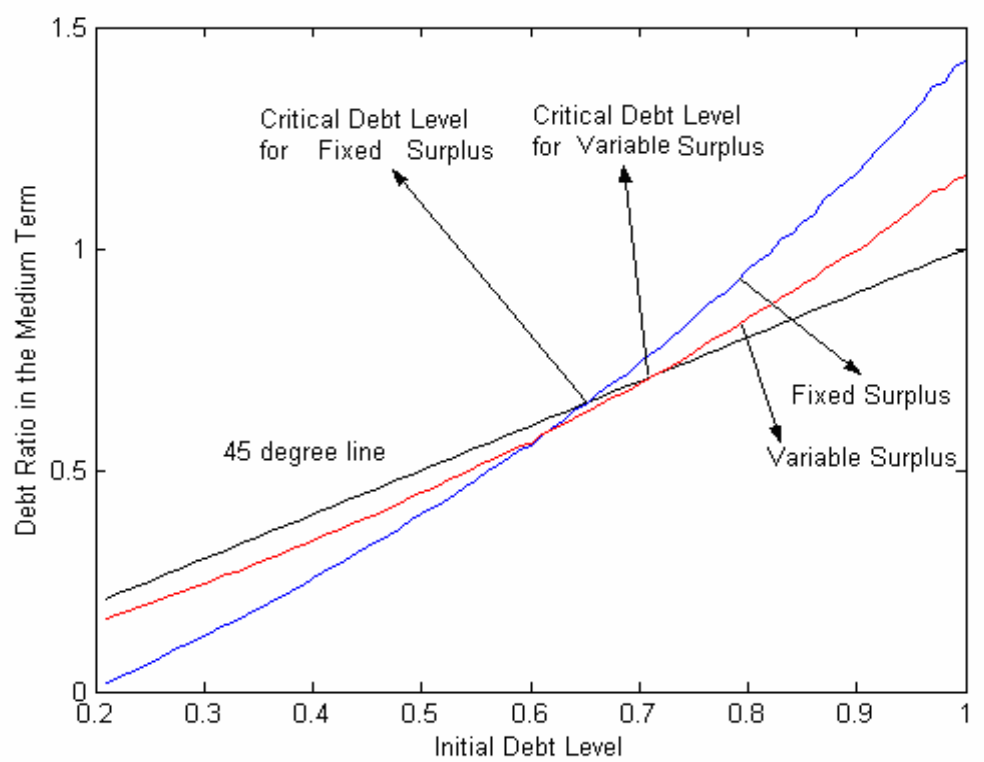

Figure 4. Average Debt Ratio in the Medium Term 
In Figure 4, the horizontal axis and the vertical axis represent, respectively, the initial debt to GDP ratio, and the debt to GDP ratio at the end of the next period which is yielded by the simulation. Points under the 45 degree line show that the next period debt ratio is lower than the initial value.

As a corollary of the probabilistic domination of the variable surplus rule over the fixed surplus rule in terms of debt sustainability, the magnitude of the primary surplus generated by the variable rule is lower than that generated by the fixed rule at debt levels below the initial debt level, set at 60 percent of GDP in our simulations (Figure 5). This can be interpreted as the desirability of the variable rule over the fixed rule.

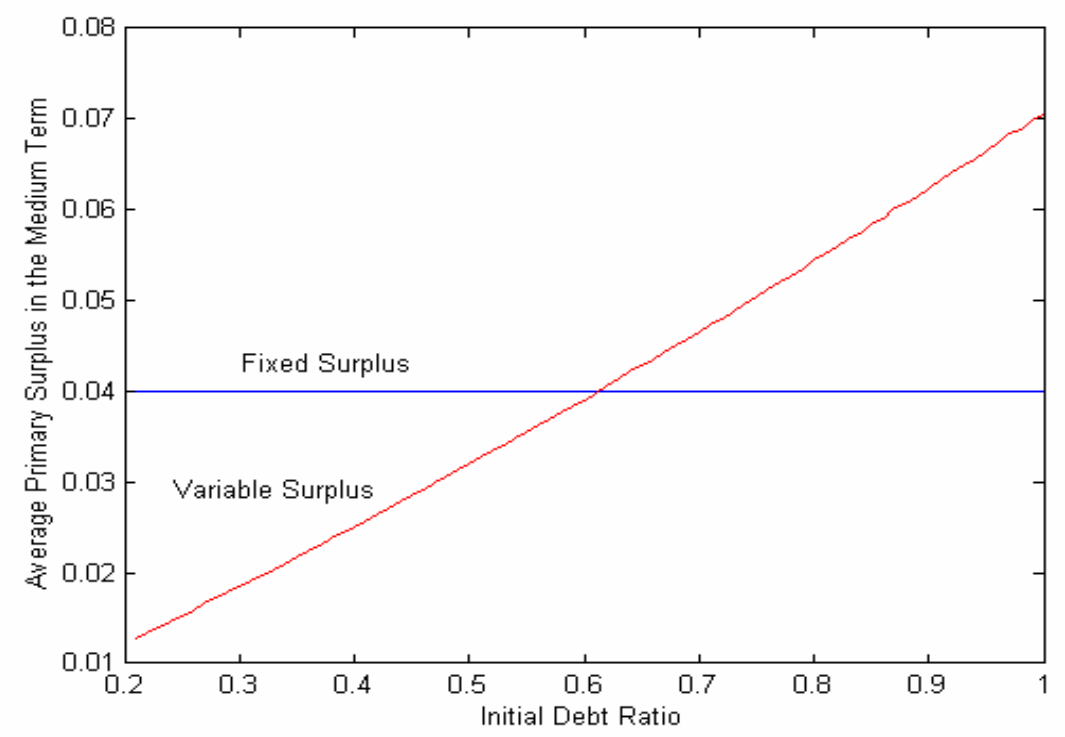

Figure 5. Primary Surplus in the Medium Term

\section{CONCLUding Remarks}

Using a simple debt dynamics equation and numerical simulations, two alternative fiscal policy rules are analyzed in this paper. The results show that a variable primary surplus rule, defined as an increasing function of the debt ratio, performs better than a fixed primary surplus rule by reducing debt sustainability concerns (measured in this paper by the probability of exceeding the critical debt level) and reducing the necessary level of the medium-term average primary surplus.

The analysis of this study can be extended by distinguishing output, the real interest, the real exchange rate and budget execution shocks and by endogenizing the growth-adjusted real interest rate function. Game theoretic analysis of the credibility issues involved in the selection between the two rules (or among further alternatives) may be another avenue for further research. 


\section{References}

Cantor, Richard, and Frank Packer, 1996, "Determinants and Impact of Sovereign Credit Ratings,” FRBNY Economic Policy Review, Vol. 2 (October), pp. 37-54.

Catao, L., and Sandeep Kapur, 2004, "Missing Link: Volatility and the Debt Intolerance Paradox,” IMF Working Paper 04/51 (Washington: International Monetary Fund).

Daban, Teresa, and others, 2003, Rules-Based Fiscal Policy in France, Germany, Italy, and Spain, IMF Occasional Paper No. 225 (Washington: International Monetary Fund).

Halpern, Laszlo, and Judith Nemenyi, 2002, "Fiscal Foundations of Convergence to European Union in the Pre-Accession Transition Countries," Discussion Paper 03/02, (Frankfurt: Economic Research Center, Deutsche Bundesbank).

Hausman, Ricardo, 2002, "Good Credit Ratios, Bad Credit Ratings: the Role of Debt Denomination,” (unpublished; Cambridge, Massachusetts: Harvard University).

$\mathrm{Hu}$, Yen-Ting, Rudiger Kiesel, and William Perraudin, 2001, "The Estimation of Transition Matrices for Sovereign Credit Ratings," Journal of Banking and Finance, Vol. 26, No. 7, 1353-1406.

Kopits, George, 2001, "Fiscal Rules: Useful Policy Framework or Unnecessary Ornament," IMF Working Paper 01/145 (Washington: International Monetary Fund). , and Steven Symanski, 1998, Fiscal Policy Rules, IMF Occasional Paper No. 162 (Washington: International Monetary Fund).

Larrain, Guillermo, Helmut Reisen, and Julia von Maltzan, 1997, "Emerging Market Risk and Sovereign Credit Ratings," OECD Development Centre Technical Paper No. 124 (Paris: OECD).

Wyplosz, Charles, 2002, “Fiscal Policy: Rules or Institutions?” CEPR Discussion Paper 3238 (London: Centre for Economic Policy Research). 